\title{
Vascular Endothelial Growth Factor and L L pocalin-2 as Markers of Early Nephron Damage in Patients with Hypertension and Obesity
}

DOI: $10.17691 /$ stm2016.8.1.20

Received July 6, 2015

S.G. Shulkina, MD, PhD, Associate Professor, Department of Internal Diseases and Polyclinic Therapy';

Engineer-Researcher';

V.V.Schekotov, MD, DSc, Professor, Head of the Department of Internal Diseases and Polyclinic Therapy ${ }^{1}$

E.N. Smirnova, MD, DSC, Professor, Head of the Department of Endocrinology and Clinical Pharmacology²;

Engineer-Researcher2:

A.A. Antipova, MD, PhD, Associate Professor, Department of Endocrinology and Clinical Pharmacology

Perm State University of Medicine named after Academician E.A. Wagner, 26 Petropavlovskaya St., Perm, 614000,

Russian Federation;

2Institute of Continuous Media Mechanics of the Ural Branch of Russian Academy of Sciences,

1 Akademik Korolev St., Perm, 614013, Russian Federation

The aim of the investigation is to evaluate the levels of vascular endothelial growth factor (VEGF) and lipocalin-2 (NGAL) as markers of early diagnosing glomerular and tubular system damage in patients with arterial hypertension (AH) and obesity.

Materials and Methods. The monitoring group consisted of 38 patients with AH of degrees I-II and stages I-II with no signs of structural, functional and organic kidney lesions who received neither statins nor therapy for hypertension. The patients' mean age was $42.3 \pm 8.3$ years. Body mass index was $38.0 \pm 10.0$. The comparison group included 15 healthy volunteers (comparable in age and sex). General clinical and laboratory examination included assessment of lipid profile, glycemia, creatinine, uric acid, body mass index, glomerular filtration rate (GFR) (formula CKD-EPI, ml/min/1.73 $\mathrm{m}^{2}$ ). VEGF, NGAL and microalbuminuria levels were determined by enzyme immunoassay using Stat-Fax photometer (Awareness Technology Inc., USA) and the appropriate kits.

Results. GFR proved to depend on the degree of obesity. There was noted a negative correlation between GFR and diastolic BP levels, a significant correlation with creatinine, cholesterol, very low density lipoproteins and uric acid levels.

Even in the presence of normal creatinine level pathological microalbumin level was diagnosed in $31.6 \%$ of patients, it was elevated in $44.7 \%$. A correlation between microalbumin value and the levels of diastolic BP, creatinine, total cholesterol was found to be positive and it was negative to GFR value. There was also established a direct correlation between VEGF and the levels of systolic BP, microalbumin and uric acid while it was negative to GFR. There was a significant correlation between microalbuminuria and NGAL level.

Conclusion. In patients with uncomplicated AH combined with obesity microalbuminuria and VEGF are the early markers of glomerular damage while NGAL is a marker of tubular injury and tubular dysfunction is not always associated with glomerular damage. Reduced GFR is associated with diastolic BP, microalbuminuria and VEGF and is independent of NGAL level.

Key words: arterial hypertension; obesity; glomerular and tubular damage; glomerular filtration rate; lipocalin; microalbuminuria; vascular endothelial growth factor.

Obesity is an independent risk factor of arterial hypertension $(\mathrm{AH})$ and chronic renal disease development and progression. It has been proved that $10 \%$ growth of body mass index increases the probability of steady 1.27-fold reduction of glomerular filtration rate (GFR) [1-3]. It has been established that histologic changes of kidney parenchyma in obese patients resemble those typical of early diabetic nephropathy prior to microalbuminuria (MAU) [4] and MAU presence is the evidence of general endothelial dysfunction in $\mathrm{AH}$ and obesity, being at the same time an early marker of glomerular dysfunction [1, 3, 4].

Fibrosis and angiogenesis mediators, including vascular endothelial growth factor (VEGF), play a significant role in nephropathy progression in $\mathrm{AH}$ and obesity [3].

Lately special attention has been paid to studying tubular-interstitial system that is involved in the pathological process in cardiac pathology earlier than the glomerule, which suggests that the preserved glomerular structure does not always imply normal nephron functioning [2]. Lipocalin-2 (NGAL) has traditionally been considered a marker of acute kidney injury, however, there have appeared studies providing the possibility to evaluate it in terms of subclinical tubular damage [5].

Thus, the issue of early glomerular and tubular dysfunction diagnosis in obese $\mathrm{AH}$ patients has not

For contacts: Sofia G. Shulkina, shulkina-s@mail.ru 
been studied well enough and search for tubular interstitial kidney injury markers remains urgent.

The aim of the investigation is to evaluate the levels of vascular endothelial growth factor and lipocalin-2 as markers of early diagnosing glomerular and tubular system damage in patients with arterial hypertension and obesity.

Materials and Methods. The studied group consisted of 38 patients (mean age $-42.3 \pm 8.3$ years, body mass index $-38.0 \pm 10.0$ ) with $\mathrm{AH}$ of degrees $\mathrm{I}-\mathrm{II}$ and stages I-II with no organic kidney lesions in the past medical history, no pathological changes in clinical urine analysis, creatinine and no ultrasound signs of anatomic or structural kidney changes. No one of the patients received statins or therapy for hypertension before.

Patients with secondary $\mathrm{AH}$, third-degree $\mathrm{AH}$ of stage III, diabetes mellitus, myocardium inflammations, systemic connective tissue diseases and cancers were not included in the study.

The comparison group consisted of 15 healthy volunteers (comparable in age and sex) (mean age $39.4 \pm 5.3$ years, body mass index $-27.0 \pm 1.3$ ).

All participants underwent general clinical and laboratory examination. The levels of lipids, plasma glucose, creatinine, uric acid, transaminase and bilirubin were determined by standard biochemical methods. Body mass index was calculated with Quetelet's formula: body mass $(\mathrm{kg}) /$ height $\left(\mathrm{m}^{2}\right)$. GFR was calculated with CKD-EPI $\mathrm{ml} / \mathrm{min} / 1.73 \mathrm{~m}^{2}$ formula. GFR reduction degree was assessed according to the national guidelines [6].

Urine marker concentration was determined using a morning urine sample. VEGF, NGAL and MAU levels were determined by enzyme immunoassay using StatFax photometer (Awareness Technology Inc., USA) and the appropriate kits: Vektor-best (Vektor-best, Russia), NGAL Rapid ELISA Kit (BioPorto Diagnostic A/S,
Denmark), ELISA Micro-Albumin (Orgentec, Germany). The study complies with the Declaration of Helsinki (adopted in June 1964 (Helsinki, Finland) and revised in October 2000 (Edinburgh, Scotland)) and was performed following approval by the Ethics Committee of Perm State Academy of Medicine. Written informed consent for participation in the study and personal data processing was obtained from every patient.

Statistical data processing was performed by means of the program Statistica 7.0 Rus. The mean, standard error of the mean, Student's t-test were used to evaluate the data with normal distribution. The data with nonnormal distribution were presented as median and interquartile interval Me [25; 75]. Nonparametric MannWhitney U-test was used to compare independent samples based on quantitative parameters. Sample differences were considered statistically significant at $p<0.05$. The relationship between parameters was assessed by regression analysis determining Spearman rank correlation coefficient. The relationship between values was considered to be strong at $R>|0.7|$, medium at $R=|0.3|$ to $|0.7|$, weak at $R<|0.3|$.

Results. In patients with obesity-associated $\mathrm{AH}$ the mean systolic arterial blood pressure (BP) level amounted to $147.9 \pm 7.1 \mathrm{~mm} \mathrm{Hg}$, diastolic arterial BP was $98.8 \pm 5.0 \mathrm{~mm} \mathrm{Hg}$. The average $\mathrm{AH}$ duration was $4.1 \pm 2.5$ years. Family history burdened with cardio-vascular diseases was present in all the patients. Dyslipidemia and hypertriglyceridemia was revealed in $90 \%$ of patients, reduced level of high-density lipoproteins in $31 \%$ and hyperglycemia (without diabetes mellitus diagnosis) was found in $68.5 \%$ of patients.

Elevated levels of total cholesterol, triglycerides, lowdensity lipoproteins, glucose, uric acid and creatinine were revealed in this group compared to the group of apparently healthy individuals (Table 1).

Table 1

Indexes of obese arterial hypertension patients compared to the group of apparently healthy individuals (M+SD)

\begin{tabular}{|lccc|}
\hline \multicolumn{1}{c}{ Parameters } & $\begin{array}{c}\text { Patients with } \mathbf{A H} \\
\text { and obesity }(\mathbf{n = 3 8 )}\end{array}$ & $\begin{array}{c}\text { Healthy } \\
(\mathbf{n = 1 5})\end{array}$ & $\mathbf{p}$ \\
\cline { 2 - 4 } Age (years) & $42.3 \pm 8.3$ & $39.4 \pm 5.3$ & 0.7 \\
\hline Waist measurement $(\mathrm{cm})$ & $113.2 \pm 11.0$ & $80.7 \pm 11.0$ & 0.0001 \\
\hline Body mass index $\left(\mathrm{kg} / \mathrm{m}^{2}\right)$ & $38.0 \pm 10.0$ & $27.0 \pm 1.3$ & 0.00001 \\
\hline Systolic BP $(\mathrm{mm} \mathrm{Hg})$ & $147.9 \pm 7.1$ & $128.3 \pm 7.2$ & 0.0001 \\
\hline Diastolic BP $(\mathrm{mm} \mathrm{Hg})$ & $98.8 \pm 5.0$ & $78.5 \pm 5.3$ & 0.0001 \\
\hline Glucose $(\mathrm{mmol} / \mathrm{L})$ & $5.8 \pm 0.8$ & $4.21 \pm 0.50$ & 0.0001 \\
\hline Total cholesterol $(\mathrm{mmol} / \mathrm{L})$ & $5.9 \pm 0.9$ & $4.0 \pm 0.7$ & 0.004 \\
\hline Low-density lipoproteins $(\mathrm{mmol} / \mathrm{L})$ & $3.62 \pm 0.70$ & $2.43 \pm 0.40$ & 0.03 \\
\hline High-density lipoproteins $(\mathrm{mmol} / \mathrm{L})$ & $1.31 \pm 0.30$ & $1.4 \pm 0.1$ & 0.3 \\
\hline Triglycerids $(\mathrm{mmol} / \mathrm{L})$ & $2.33 \pm 1.10$ & $0.57 \pm 0.11$ & 0.001 \\
\hline Creatinine $(\mu \mathrm{mol} / \mathrm{L})$ & $78.6 \pm 12.5$ & $66.0 \pm 10.1$ & 0.01 \\
\hline Uric acid $(\mathrm{mmol} / \mathrm{L})$ & $391.4 \pm 45.4$ & $241.5 \pm 86.1$ & 0.009 \\
\hline Glomerular filtration rate $\left(\mathrm{ml} / \mathrm{min} / 1.73 \mathrm{~m}^{2}\right)$ & $88.5 \pm 5.8$ & $112.7 \pm 7.6$ & 0.001 \\
\hline
\end{tabular}


Table 2

Concentration of renal damage biomarkers in the groups

\begin{tabular}{|c|c|c|c|}
\hline Indexes & Patients with AH and obesity ( $n=38)$ & Healthy $(n=15)$ & p \\
\hline Microalbumin (mg/ml) & 25.8 (11.7; 34.0); [8.6; 56.5] & $9.4(5.4 ; 13.2) ;[1.4 ; 20.0]$ & 0.001 \\
\hline Vascular endothelial growth factor (pg/ml) & 79.0 (28.0; 96.2); [5.0; 342.0] & $15.8(9.1 ; 21.7) ;[2.1 ; 46.4]$ & 0.0001 \\
\hline Lipocalin-2 (pg/ml) & $14.8(0.0 ; 20.0) ;[0.0 ; 50.0]$ & $1.25(0.0 ; 2.5) ;[0.0 ; 5.0]$ & 0.001 \\
\hline
\end{tabular}

$\mathrm{N}$ o t e. Percentiles (25\%; $75 \%)$ are specified in parenthesis and there are min and max values in square brackets.

GFR was found to be slightly reduced in $\mathrm{AH}$ patients compared to the control. The study showed that optimal GFR (>90 ml/min/1.73 $\mathrm{m}^{2}$ ) was observed in $37.1 \%$ of patients $(n=13)$; it was slightly reduced in $37.1 \%(>60$, but $\left.<90 \mathrm{ml} / \mathrm{min} / 1.73 \mathrm{~m}^{2}\right)$; in $8.6 \%$ of patients it was moderately reduced $\left(>45\right.$, but $\left.<60 \mathrm{ml} / \mathrm{min} / 1.73 \mathrm{~m}^{2}\right)$; elevated GFR (>110 ml/min/1.73 $\mathrm{m}^{2}$ ) was revealed in $17 \%$ of patients. Significant GFR elevation as well as reduction was found in patients with third-degree obesity.

Data analysis made it possible to identify the relationships between parameters. Negative correlation between GFR and diastolic BP level $(r=-0.4 ; p=0.04)$ was established and there was direct significant correlation between waist circumference value and the levels of diastolic BP $(r=0.43 ; p=0.03)$, uric acid $(r=0.5$; $p=0.04)$, triglycerides $(r=0.36 ; p=0.03)$, very low-density lipoproteins $(r=0.5 ; p=0.04)$.

There was revealed significant correlation between creatinine and cholesterol levels $(r=0.42 ; p=0.045)$, very low-density lipoproteins $(r=0.5 ; p=0.04)$ and uric acid $(r=0.48 ; p=0.03)$.

The levels of kidney injury markers, VEGF, NGAL and $M A U$, were significantly higher in the group of obese $\mathrm{AH}$ patients (Table 2). Pathological MAU level (>30 mg/ml) was diagnosed in $31.6 \%$ of them, $44.7 \%$ had elevated MAU level (10-29 mg/ml).

A positive correlation between $\mathrm{MAU}$ value and diastolic BP level $(r=0.7 ; p=0.02)$, creatinine $(r=0.42$; $p=0.03)$, total cholesterol $(r=0.41 ; p=0.04)$ was found and the correlation between MAU and GFR values $(r=-0.5 ; p=0.03)$ was negative.

There was also a direct correlation between urinary VEGF and systolic BP levels $(r=0.49 ; p=0.04)$, MAU $(r=0.47 ; p=0.04)$ and uric acid, the correlation being negative with GFR $(r=-0.46 ; p=0.03)$.

There was a significant correlation between NGAL and MAU level ( $r=0.46 ; p=0.04)$.

Discussion. Today GFR is looked at not only as a kidney injury marker but also as a risk factor of adverse outcomes in individuals with and without cardio-vascular diseases. ALLHAT study shows that in AH patients with one or more risk factors of cardio-vascular diseases optimal GFR is identified in $15 \%$ of patients, insignificant reduction is observed in $56.7 \%$, while $17.2 \%$ have moderate reduction (the average respondents' age amounts to 66 years). A number of studies prove that with GFR reduced by $5 \mathrm{ml} / \mathrm{min} / 1.73 \mathrm{~m}^{2}$ cardio-vascular mortality risk increases by $26 \%$, and 90 to $60 \mathrm{ml} / \mathrm{min} /$
$1.73 \mathrm{~m}^{2}$ reduction increases the risk 4 times. Moreover, the correlation between GFR reduction and the outcomes is independent of the previous presence of $\mathrm{AH}$, diabetes mellitus, lipid profile or endothelial dysfunction [7, 8].

Our study has revealed insignificant GFR reduction in $37 \%$ of patients, moderate reduction in $8.6 \%$. A lower proportion of patients with reduced GFR can be explained by a younger age of the group (42 years on average) as well as shorter $\mathrm{AH}$ duration (2-4 years).

Retrospective analysis of research works devoted to GFR calculation allowed us to establish the critical GFR level for cardio-vascular prognosis (the average age in the studied population amounted to 55.5 years): GFR level reduction to $75 \mathrm{ml} / \mathrm{min} / 1.73 \mathrm{~m}^{2}$ is unfavorable in terms of cardio-vascular outcomes [3, 7, 9]. In our group $26.3 \%$ of patients had VEGF lower than $75 \mathrm{ml} / \mathrm{min} / 1.73 \mathrm{~m}^{2}$.

The latest findings consider MAU to be a marker of early renal dysfunction, generalized microvascular blood-flow impairment and total cardio-vascular risk. On average, MAU is revealed in $30-40 \%$ of patients and in a number of cases in $72 \%$, which is likely to be associated with $\mathrm{AH}$ duration and severity [4, 10]. In patients with $\mathrm{AH}$, degree $\mathrm{I}-\mathrm{Il}$, the average MAU frequency is $12-22 \%$. However, when $\mathrm{AH}$ is accompanied by obesity MAU frequency increases up to $30-40 \%[1,3]$. In our study MAU has been revealed in $31.6 \%$ of patients, which is quite in line with the literature data. We have also found that GFR reduction is accompanied by MAU, which confirms the presence of renal damage.

A number of investigations show that a link between MAU and cardio-vascular risk is likely to be excessive VEGF production that not only raises vascular permeability promoting hemorrhagic and atherosclerotic processes but also increases permeability of glomerular filter for albumin [2, 3]. VEGF has proved to be a marker of early kidney damage in mild $\mathrm{AH}$ patients, a direct correlation between MAU and VEGF level being revealed [11]. The obtained data demonstrate both presence of endothelial dysfunction and activation of fibrogenesis mechanisms which are the links of remodeling processes of renal microvascular blood-flow in hypertensive nephropathy. In our investigation VEGF level was statistically significantly higher in the group of $\mathrm{AH}$ patients and we also found a direct correlation between MAU and VEGF level. Besides, a negative correlation between VEGF and GFR was established, 
which also confirms that VEGF serves as a marker of glomerular damage.

Investigations demonstrate that elevated level of urinary NGAL in patients with $\mathrm{AH}$, stage II-III, provides evidence of renal function impairment regardless of $\mathrm{AH}$ severity and duration [11]. Our findings show this as well: elevated level of urinary NGAL was revealed in patients with $\mathrm{AH}$ of stage I-II. Elevated level of urinary NGAL as a sign of tubular dysfunction was found in $47.3 \%$ of $\mathrm{AH}$ patients and some of them $(13 \%, n=5)$ had this elevation in the presence of optimal MAU level and normal GFR.

The obtained result suggests that in $\mathrm{AH}$ not only the glomerular system is involved in the pathological process but kidney tubule as well. Consequently, NGAL can be considered an early marker of nephron damage in $\mathrm{AH}$.

Thus, elevated levels of urinary VEGF, MAU and NGAL can be considered early markers of renal damage in young obese patients on early stages of arterial hypertension, these changes occurring prior to GFR changes.

Conclusion. In patients with uncomplicated $\mathrm{AH}$ of stage I-II combined with obesity elevated levels of microalbumin and vascular endothelial growth factor are the early markers of glomerular damage and lipocalin-2 is a marker of tubular injury, tubular dysfunction not always being associated with glomerular damage. Reduced glomerular filtration rate associated with diastolic BP, microalbumin and vascular endothelial growth factor levels is independent of lipocalin-2 level.

Study Funding. The study was supported by Russian Research Foundation (grant No.14-15-00809).

Conflicts of interest. The authors declare no conflicts of interest to disclose.

\section{References}

1. Sharipova G.Kh., Chazova I.E. Renal pathology features in arterial hypertension patients with and without metabolic syndrome. Rossiyskiy kardiologicheskiy zhurnal 2008; 6(74): $1-10$.
2. Arutiunov G.P., Oganezova L.G., Sokolova A.V. Assessment of renal function, involvement of renal glomeruli and tubulo-interstitium in patients with arterial hypertension. Klinicheskaya nefrologiya 2011; 6: 16-24.

3. Krasnova E., Fedorova E., Kutyrina I., Fomin V. Renal disease in obese: clinical, pathogenic and therapeutic aspects. Vrach 2005; 6: 6-9.

4. Litvin A. Microalbuminuria: clinical value. Vrach 2011; 9: 7-13.

5. Velkov V.V. NGAL - the renal troponin: the early marker of the acute kidney injury: the urgency for nephrology and cardiac surgery. Kliniko-laboratornyy konsilium 2011; 2: 90-100.

6. Smirnov A.V., Schilov E.M., Dobronravov V.A., Kayukov I.G., Bobkova I.N., Shcveczov M.U., Czigin A.N., Schutov A.M. National recommendations. Chronic illness of kidneys: main principles of screening, diagnostics, preventive maintenance and approaches to treatment. Klinicheskaya nefrologiya 2012; 4: 4-26.

7. Smirnov A.V., Sedov V.M., Lhaahuu Od-Erdene, Kayukov I.G., Dobronravov V.A., Panina I. Yu. Reduction of the glomerular filtration rate as an independent risk factor of the cardio-vascular disease. Nefrologiya 2006; 10(4): 7-17.

8. Shemetov V.G. Khronicheskaya bolezn' pochek u bol'nykh arterial'noy gipertenziey: chastota, faktory riska razvitiya, kliniko-prognosticheskoe znachenie. Avtoref. dis. ... kand. med. nauk [Chronic kidney disease in patients with hypertension: the frequency, risk factors, clinical and prognostic value. PhD Thesis]. Irkutsk; 2012.

9. Kryachkova A.A., Savelyeva S.A., Gallyamov M.G., Shestakova M.V., Kutiryna I.M. The role of obesity in renal injury in patients with metabolic syndrome. Nefrologiya i dializ 2010; 12(1): 34-38.

10. Kuzmin O.B., Pugaeva M.O., Chub S.V. Mild renal dysfunction in patients with essential hypertension: clinical signs and drug therapy. Nefrologiya 2004; 8(3): 15-21.

11. Nanchikeeva M.L. Rannyaya stadiya porazheniya pochek u bol'nykh gipertonicheskoy bolezn'yu: klinicheskoe znachenie, printsipy profilaktiki. Avtoref dis. ... dokt. med. nauk [The early stage kidney disease in hypertensive patients: clinical implications, prevention principles. DSc Thesis]. Moscow; 2010. 